\title{
Shape and Target Strength of Vesicles of two Sargassum Species Common to the Coastal Waters of Japan
}

\author{
Kenji MINAMI (Graduate School of Environmental Science, Hokkaido University) \\ (Present affrication; Field Science Education and Research Center, Kyoto University) \\ Akira HAMANO, Takeshi NAKAMURA (National Fisheries University) \\ Yoshimi TAKAO (National Research Institute of Fisheries Engineering) \\ Hiroki YASUMA, Kazushi MIYASHITA (Hokkaido University) \\ minami@ees.hokudai.ac.jp \\ (Present address; k.minami@ky3.ecs.kyoto-u.ac.jp)
} (Received 30 November 2009)

\begin{abstract}
:
The size of vesicles and amount of gas they contain is a major factor in the acoustic scattering of Sargassum plants. Here we investigate the morphological character of the vesicles and gas, and their theoretical and experimental target strength (TS) for two Sargassum species, Sargassum macrocarpum and S. siliquastrum. Both species are abundant in the coastal waters of Japan. A total of 593 vesicles were measured using a soft X-ray system, and their gas shapes were applied to two theoretical TS models (nonresonance and resonance). Experimental TS were obtained at 70 and $200 \mathrm{kHz}$ using quantitative echo sounders in a freshwater tank. Gas fields were found in 418 vesicles, and the gas radius and external size of the vesicles were linearly related in both species. The theoretical TS of the non-resonance model was similar to the experimental TS of large vesicles $(\geq 4.1 \mathrm{~mm}$ at $70 \mathrm{kHz}, \geq 2.8 \mathrm{~mm}$ at $200 \mathrm{kHz}$ ), whereas the theoretical TS of the resonance model was similar to the experimental TS of small vesicles $(\leq 3.1 \mathrm{~mm}$ at 70 $\mathrm{kHz}, \leq 1.9 \mathrm{~mm}$ at $200 \mathrm{kHz}$ ). Finally, we estimated TS-size equations according to the gas-size relationships and compared the results.
\end{abstract}

Classification: Fisheries Acoustics, Bioacoustics

Keyword: Airbladder resonance, Sargassum plant, Target strength, Vesicle.

\section{INTRODUCTION}

The perennial brown algae Sargassum macrocarpum and S. siliquastrum, which are distributed widely around Japan, form dense populations or "Sargassum beds" in coastal areas". Sargassum beds play important ecological roles in the coastal area due to their high productivity ${ }^{2,3)}$. They are also important for coastal fauna as nursery, feeding, and hiding grounds $^{4}$. Therefore, quantitative information on them is required for the assessment of coastal marine 
ecosystems ${ }^{5)}$. Previously, direct sampling methods ${ }^{5)}$, such as diving and grabs, have been used for biomass estimates. However, these direct methods require considerable time and effort underwater. To avoid this problem, acoustic measurement has been suggested as a useful alternative ${ }^{6}$.

For acoustic measurement, the target strength $(\mathrm{TS})^{7)}$ of an individual organism is required to estimate the biomass. Hence, we need to know the TS of Sargassum plants to estimate their biomass. A Sargassum plant consists of clusters of vesicles that contain small gas bubbles ${ }^{8}$. Shibata suggested that the TS of vesicles should first be calculated to estimate the TS of a "whole" Sargassum plant ${ }^{8)}$. He also suggested that acoustic resonance of vesicles would affect the TS of a Sargassum plant because the vesicles and gas bubbles are very small. However, few reports have examined the relationship between the external and gas sizes of the vesicle, and no work has considered the effect of resonance on the vesicle TS.

We investigated the external and gas sizes of vesicles in detail using a soft X-ray system. We report the effect of resonance on the vesicle TS based on a comparison of the theoretical models and experimental results.

\section{MATERIALS AND METHODS}

\subsection{Sargassum plant samples}

Four plants (three $S$. macrocarpum and one $S$. siliquastrum) were collected in coastal waters (about $5 \mathrm{~m}$ deep) around Shimonoseki, in the Yamaguchi prefecture of Japan, by skin diving on April 15 and May 14, 2005. To avoid making air bubbles on the surface of the vesicles, we collected each plant in a plastic specimen bottle with seawater and sealed it underwater. The bottles were preserved for three days in a refrigerator at $10{ }^{\circ} \mathrm{C}$. In the laboratory, all vesicles were used for subsequent measurements (a total of 343 S. macrocarpum and 259 S. siliquastrum vesicles).

\subsection{Internal and external vesicle measurements}

A soft X-ray radiation and imaging unit (Protest-100, Softex Co.) was used to observe the gas field in a vesicle. We measured the major and minor axes of the vesicle and the gas field on a soft X-ray image (Fig. 1). The major axis $\left(\Phi_{L}\right)$ was defined as the longest line of the vesicle and the gas field. The minor axis $\left(\Phi_{S}\right)$ was defined as the longest line that crossed the major axis at right angles. Then, we calculated the equivalent radius of the vesicle $(A)$ and the gas field $(a)$ by the equation ${ }^{9)}$

$$
\text { equivalent radius }(A \text { or } a)=\frac{\left(\Phi_{L} \times \Phi_{s}^{2}\right)^{1 / 3}}{2}
$$

To estimate the TS theoretically, an oval sphere can be assumed an equivalent sphere when the ratio between $\Phi_{L}$ and $\Phi_{S}$ is in the range $1: 2^{10)}$. We found the $\Phi_{L}$ and $\Phi_{S}$ of all vesicles to be in the range $1: 2$.

\subsection{TheoreticalTS estimation of a vesicle}

We considered the gas of vesicle as free bubble, since the shell of vesicle was soft and the space

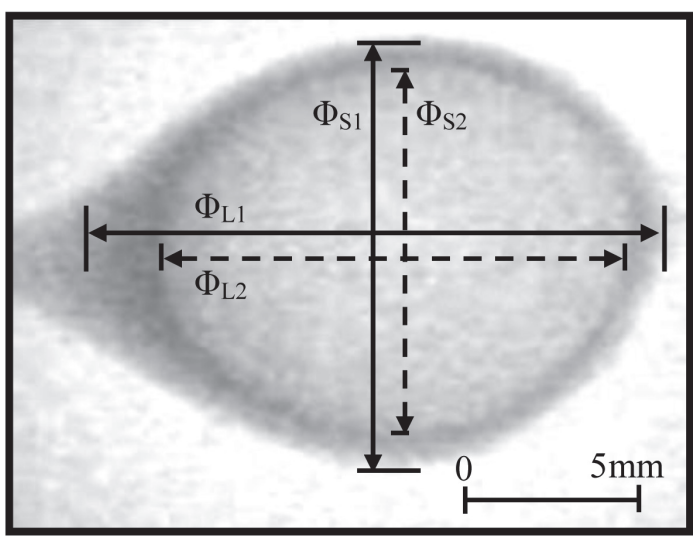

Fig. 1 A soft X-ray image of a vesicle. The solid line shows the major $\left(\Phi_{L 1}\right)$ and minor $\left(\Phi_{S 1}\right)$ axes of the outer shell, and the dashed line the major $\left(\Phi_{L 1}\right)$ and minor $\left(\Phi_{S 1}\right)$ axes of the gas field. 
between the shell and the gas was filled with liquid. The theoretical TS $\left(T S_{\mathrm{t}}\right)$ is ${ }^{7}$

$$
T S_{\mathrm{t}}=10 \log \frac{\sigma}{4 \pi},
$$

where $\sigma$ is the acoustic cross-section ${ }^{7)}$. $\sigma$ can be expressed by a non-resonance or resonance model. When the parameter $k a$ is large (e.g., $k a>1 ; k a=2 \pi \mathrm{a}$ / $\lambda$, where $k$ is the wavenumber and $\lambda$ the wavelength), $\sigma$ is expressed by the non-resonance model. Then, ${ }^{11)}$

$$
\sigma=\pi a^{2}
$$

Then, the $T S_{\mathrm{t}}$ can be obtained by Eqs. (2) and (3) as

$$
T S_{\text {t_non-resonance }}=10 \log \frac{a^{2}}{4} \text {. }
$$

If $k a$ is small (e.g., $k a<1$ ), $\sigma$ is expressed by the resonance model ${ }^{12)}$

$$
\sigma=\frac{4 \pi a^{2}}{\left\{\left(f_{r}^{2} / f^{2}\right)-1\right\}^{2}+\delta^{2}},
$$

where $f$ is the frequency of the incident echo $(\mathrm{Hz}), \delta$ is a dumping constant, and $f_{r}$ is the resonant frequency (Hz). In this study, we considered the $\delta$ as 0.1 , which is the value of free bubble in Devin's study ${ }^{13)}$. The $f_{r}$ is defined as ${ }^{14)}$

$$
f_{r}=\frac{3.26}{a}(1+0.1 Z)^{1 / 2},
$$

where $Z$ is the depth of the target (m). Then, in the resonance model, the $T S_{\mathrm{t}}$ is given by Eqs. (2) and (5) as

$$
T S_{\mathrm{t} \_ \text {non-resonance }}=10 \log \frac{a^{2}}{\left\{\left(f_{r}^{2} / f^{2}\right)-1\right\}^{2}+\delta^{2}} .
$$

\subsection{ExperimentalTS measurement of a vesicle}

Experimental TS $\left(T S_{\mathrm{e}}\right)$ vesicle measurements were performed at the National Research Institute of Fisheries Engineering (NRIFE) in Japan. An indoor freshwater tank $(10 \mathrm{~m} \times 10 \mathrm{~m} \times 15 \mathrm{~m})$ with $70 \mathrm{kHz}$ and $200 \mathrm{kHz}$ echo sounders was used to measure $T S_{\mathrm{e}}$ (Table 1) ${ }^{15)}$. Prior to the measurements, the experimental system was calibrated using a $38 \mathrm{~mm}$ tungsten carbide sphere. Although it is better to measure vesicles in seawater, the main component of the vesicle was gas, and hence the difference in the TS measured in seawater or in freshwater is negligible. Four S. macrocarpum and six S. siliquastrum vesicles were measured. An individual sample was suspended about $2 \mathrm{~m}$ depth in the tank. Each vesicle was stitched with nylon lines (diameter: $0.25 \mathrm{~mm}$ ) and fixed using its own buoyancy above echo sounders. Pulses were transmitted to the suspended sample from bottommounted echo sounders, and backscattered echoes were recorded (Fig. 2). We recorded 50 pings in each vesicle. Additional details of the experimental setup and data recording process are given in Sawada ${ }^{15}$.

\section{RESULTS}

\subsection{Measurement of vesicle}

Measurements of the vesicle and gas fields are given in Table 2. In both species, some vesicles contained gas, whereas others did not. The vesicles without gas were filled with liquid. In $S$. macrocarpum, 199 of 343 vesicles contained gas. The equivalent radius of the vesicle with gas $(A)$ ranged from 1.3 to $7.1 \mathrm{~mm}$, and the equivalent radius of the gas field (a) ranged from 0.5 to $6.0 \mathrm{~mm}$. The $A$ of the vesicles without gas ranged from 0.8 to $2.7 \mathrm{~mm}$. In $S$. siliquastrum, 217 of 259 vesicles contained gas. The $A$ of the vesicle with gas ranged from 1.7 to $6.0 \mathrm{~mm}$, and

Table 1 Setup of echo sounder in the tank experiment

\begin{tabular}{cccc}
\hline Transducer & $\begin{array}{c}\text { Frequency } \\
(\mathrm{kHz})\end{array}$ & $\begin{array}{c}\text { Pulse length } \\
(\mathrm{ms})\end{array}$ & $\begin{array}{c}\text { Beam width } \\
\text { (degree) }\end{array}$ \\
\hline ES470 (Simrad) & 70 & 0.5 & 11.0 \\
KFC-3000 (Kaijo) & 200 & 0.6 & 10.3 \\
\hline
\end{tabular}




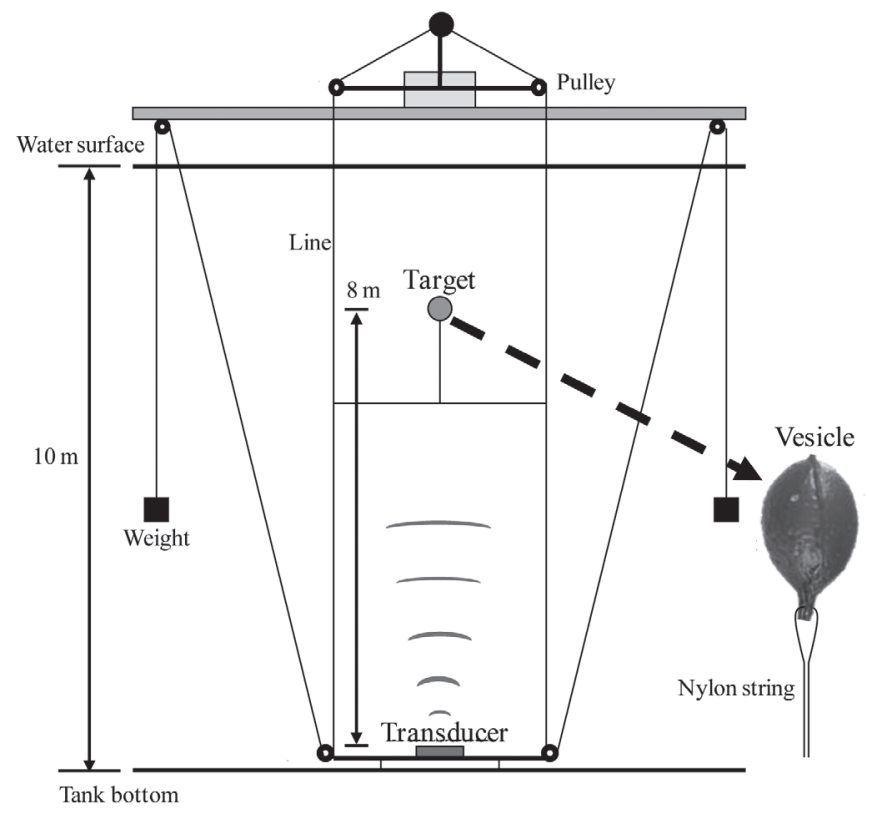

Fig. 2 Apparatus for the experimental measurement of TS. Transducers (70 and $200 \mathrm{kHz}$ ) were mounted on the bottom of the tank. A vesicle was fixed with nylon string. The distance between the bottom and the water surface was about $10 \mathrm{~m}$, and that between the transducer and the vesicle was about $8 \mathrm{~m}$.

Table 2 Shape of vesicle as measured by the X-ray system

\begin{tabular}{cccccc}
\hline \multirow{2}{*}{ Species } & \multicolumn{2}{c}{ Vesicle with gas } & & Vesicle without gas \\
\cline { 3 - 4 } S. macrocarpum & $A(\mathrm{~mm})$ & $a(\mathrm{~mm})$ & & $A(\mathrm{~mm})$ \\
\hline \multirow{2}{*}{$\begin{array}{c}\text { S. siliquastrum } \\
\text { range }\end{array}$} & $1.3-7.1$ & $0.5-6.0$ & & $0.8-2.7$ \\
& $\left(\begin{array}{c}\text { range } \pm \text { SD } \\
\text { n, Ave } \pm \text { SD }\end{array}\right)$ & $199,4.0 \pm 1.4$ & $199,2.7 \pm 1.5$ & & $144,1.8 \pm 0.4$ \\
\hline
\end{tabular}

a ranged from 0.5 to $5.3 \mathrm{~mm}$. The $A$ of the vesicle without gas ranged from 1.1 to $2.9 \mathrm{~mm}$. Vesicles with gas were used in subsequent TS computation because acoustic scattering of the vesicle without gas were considered to be negligible ${ }^{16)}$.

The relationship between the $A$ and $a$ of the vesicles with gas is shown in Fig. 3. We found the following linear relationships:

$$
\begin{aligned}
& a=1.1 A-1.6 \quad \text { (S. macrocarpum }) \\
& a=1.1 A-1.2 \quad \text { (S. siliquastrum }) .
\end{aligned}
$$

The R-square values were 0.97 and 0.98 , respectively.

\subsection{Theoretical and experimental TS of the vesicles}

Theoretical TS ( $T S_{\mathrm{t} \_ \text {non-resonance }}$ and $\left.T S_{\mathrm{t}_{\text {_resonance }}}\right)$ estimated by the non-resonance and resonance models (Eqs. 4 and 7) are shown in Fig. 4. In all the ranges of $a$ computed in this study, the $T S_{\mathrm{t}_{\mathrm{r}} \text { resonance }}$ was several decibels higher than the $T S_{\mathrm{t} \_n o n-r e s o n a n c e}$. In both models, TS values increased rapidly with $a$, until $1 \mathrm{~mm}$. After this, the slopes became relatively gentle but continued to increase. The experimental TS $\left(T S_{\mathrm{e}}\right)$ measured in the water tank is shown in Table $\mathbf{3}$ and plotted in Fig. 

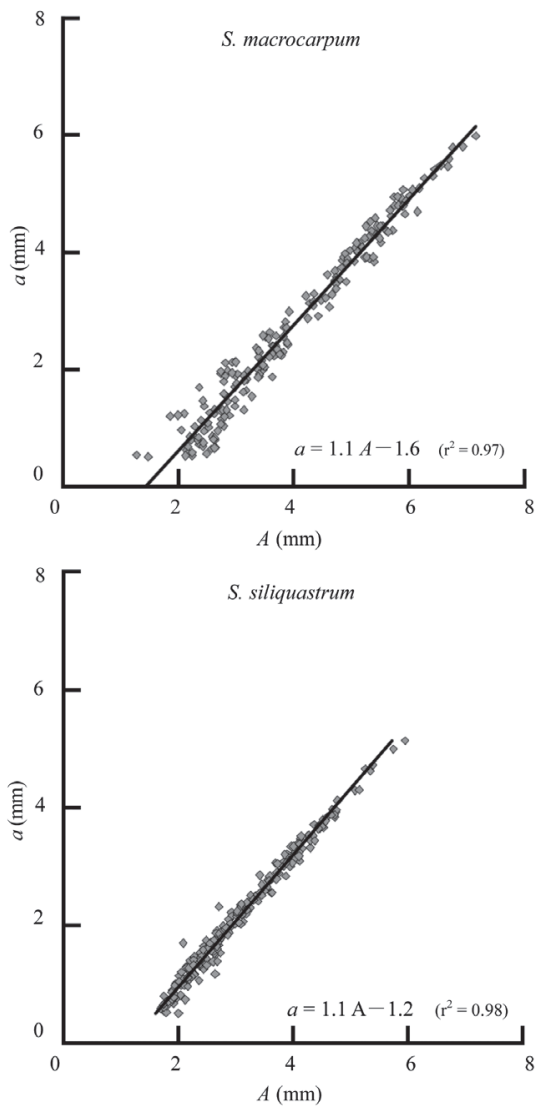

Fig. 3 The relationship between $A$ (the equivalent radius of vesicle) and $a$ (the equivalent radius of gas) for $S$. macrocarpum and S. siliquastrum.

4. In $S$. macrocarpum, the $T S_{\mathrm{e}}$ ranged from -56.9 to $-51.7 \mathrm{~dB}$ at $70 \mathrm{kHz}$ and from -60.3 to $-50.9 \mathrm{~dB}$ at 200 kHz. In S. siliquastrum, the $T S_{\mathrm{e}}$ ranged from -54.8 to $-52.7 \mathrm{~dB}$ at $70 \mathrm{kHz}$ and from -58.5 to $-51.8 \mathrm{~dB}$ at 200 kHz. At $70 \mathrm{kHz}$, the $k a$ of relatively small vesicles ( $A$ $\leq 3.1 \mathrm{~mm}, a \leq 2.2 \mathrm{~mm}$ ) were smaller than 1 . At 200 $\mathrm{kHz}$, the $k a$ of all vesicles were larger than 1 . The $T S_{\mathrm{e}}$ difference between $70 \mathrm{kHz}$ and $200 \mathrm{kHz}\left(\Delta T S_{\mathrm{e}}: 70\right.$ $\mathrm{kHz}-200 \mathrm{kHz}$ ) became larger as the vesicle became smaller. In small vesicles $(1.9 \leq A \leq 3.1 \mathrm{~mm}, 1.2 \leq a \leq$ $2.2 \mathrm{~mm}$ ), the $\Delta T S_{\mathrm{e}}$ were 2.5 to $3.7 \mathrm{~dB}$. In large vesicles $(4.1 \leq A \leq 6.3 \mathrm{~mm}, 3.1 \leq a \leq 5.3 \mathrm{~mm})$, the $\Delta T S_{\mathrm{e}}$ were -0.9 to $2.5 \mathrm{~dB}$ (Table 3 ).

At $70 \mathrm{kHz}$, the $T S_{\mathrm{e}}$ (closed symbol in Fig. 4) of large vesicles ( $A \geq 4.1 \mathrm{~mm}, a \geq 3.4 \mathrm{~mm}, k a \geq 1.03$ ) were similar to the $T S_{\mathrm{t} \_n o n-r e s o n a n c e}$. However, the $T S_{\mathrm{e}}$ of small vesicles ( $A \leq 3.1 \mathrm{~mm}, a \leq 2.2 \mathrm{~mm}, k a=0.67$ ) were similar to the $T S_{\mathrm{t} \_ \text {resonance }}$ values (Fig. 4, Table 3). At $200 \mathrm{kHz}$, the pattern was repeated: the $T S_{\mathrm{e}}$ (open symbol in Fig. 4) of large vesicles ( $A \geq 2.8 \mathrm{~mm}, a \geq$ $1.8 \mathrm{~mm}, k a \geq 1.56)$ were similar to the $T S_{\mathrm{t} \_ \text {non-resonance, }}$, whereas the $T S_{\mathrm{e}}$ of small vesicles ( $A=1.9 \mathrm{~mm}, a=1.2$ $\mathrm{mm}, k a=1.04)$ were similar to the $T S_{\mathrm{t} \_ \text {resonance }}$ (Fig. 4 , Table 3).

\section{DISCUSSION}

Gas has a critical effect on the intensity of acoustic scattering ${ }^{17)}$. Reliable prediction of the occurrence and size of gas bubbles from the external shape is therefore very important to estimate the acoustic characteristics of a vesicle. Our results for both species showed that not all of the vesicles contained gas, and significant linear relationships were found between external size and gas size (Eqs. 8 and 9). The size ranges of gas bubbles and the relationships between external size and gas size provided by this study (Table 2) will be helpful for predicting the gas shape and acoustic character of both species. However, the overlap of size ranges between the cases with and without gas (Table 2) could lead to bias in such predictions. Moreover, seasonal changes of the amount of gas in a vesicle have been reported in some Sargassum species ${ }^{18,19)}$. In future work, more typological sampling and analysis of the mechanisms behind variations in the gas amount are needed to increase the accuracy of these predictions.

A comparison between theoretical models and experimental measurements showed that the $T S_{\mathrm{e}}$ of relatively large vesicles $(A>4.1 \mathrm{~mm})$ was close to that of the non-resonance model (Eq. 4), whereas the $T S_{\mathrm{e}}$ of relatively small vesicles $(A<3.1 \mathrm{~mm})$ was closer to that of the resonance model (Eq. 7, Fig. 4, Table 3). Our results will be useful for the selection of theoretical models (Eqs. 4 or 7). However, it has 


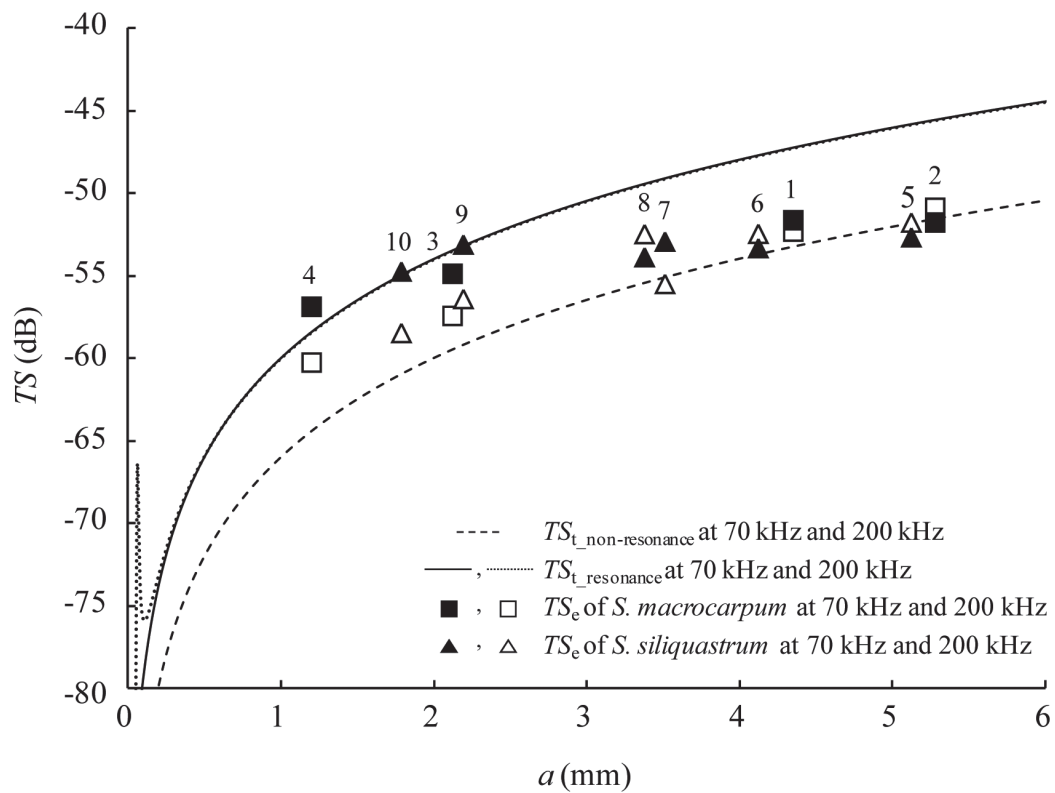

Fig. 4 The relationship between the equivalent gas radius and the TS according to theoretical models and experimental measurements. The lines are the $T S_{\mathrm{t} \_n o n-r e s o n a n c e}$ at $70 \mathrm{kHz}$ and $200 \mathrm{kHz}$ (dashed line), the $T S_{\mathrm{t} \_ \text {resonance }}$ at $70 \mathrm{kHz}$ (solid line) and the $T S_{\mathrm{t} \_ \text {resonance }}$ at $200 \mathrm{kHz}$ (dotted line). The squares are the $T S_{\mathrm{e}}$ of $S$. macrocarpum at $70 \mathrm{kHz}$ (closed square) and $200 \mathrm{kHz}$ (open square). The triangles are the $T S_{\mathrm{e}}$ of S. siliquastrum at $70 \mathrm{kHz}$ (closed triangle) and $200 \mathrm{kHz}$ (open triangle). Each number in the figure corresponds in the individual number in Table 3.

Table 3 Results of the experimental TS measurements $\left(T S_{\mathrm{e}}\right)$. Differences between the theoretical and experimental TS values of equivalent size are also shown $\left(T S_{\mathrm{t} \text { non-resonance }}-T S_{\mathrm{e}}\right.$ and $\left.T S_{\mathrm{t} \_ \text {resonance }}-T S_{\mathrm{e}}\right) . \Delta T S_{\mathrm{e}}$ is the difference in $T S_{\mathrm{e}}$ between 70 and 200 $\mathrm{kHz}\left(T S_{\mathrm{e}}\right.$ [at $\left.70 \mathrm{kHz}\right]-T S_{\mathrm{e}}$ [at $\left.\left.200 \mathrm{kHz}\right]\right)$

\begin{tabular}{|c|c|c|c|c|c|c|c|c|c|c|c|c|}
\hline \multirow[b]{2}{*}{ Species } & \multirow[b]{2}{*}{ No. } & \multirow[b]{2}{*}{$\begin{array}{c}A \\
(\mathrm{~mm})\end{array}$} & \multirow[b]{2}{*}{$\begin{array}{c}a \\
(\mathrm{~mm})\end{array}$} & \multicolumn{4}{|c|}{$70 \mathrm{kHz}$} & \multicolumn{4}{|c|}{$200 \mathrm{kHz}$} & \multirow[b]{2}{*}{$\Delta T S_{\mathrm{e}}$} \\
\hline & & & & $k a$ & $\begin{array}{r}T S_{\mathrm{e}} \\
(\mathrm{dB})\end{array}$ & $\begin{array}{c}T S_{\mathrm{t} \_ \text {non-resonance }} \\
-T S_{\mathrm{e}}(\mathrm{dB})\end{array}$ & $\begin{array}{l}T S_{\text {t_resonance }} \\
-T S_{\mathrm{e}}(\mathrm{dB}) \\
\end{array}$ & $k a$ & $\begin{array}{c}T S_{\mathrm{e}} \\
(\mathrm{dB})\end{array}$ & $\begin{array}{l}T S_{\mathrm{L} \_n o n-r e s o n a n c e} \\
-T S_{\mathrm{e}}(\mathrm{dB})\end{array}$ & $\begin{array}{l}T S_{\text {t_resonance }} \\
-T S_{\mathrm{e}}(\mathrm{dB}) \\
\end{array}$ & \\
\hline \multirow{4}{*}{ S. macrocarpum } & 1 & 6.3 & 4.4 & 1.32 & -51.7 & -1.52 & 4.48 & 3.78 & -52.4 & -0.8 & 5.2 & 0.7 \\
\hline & 2 & 5.6 & 5.3 & 1.60 & -51.8 & 0.32 & 6.22 & 4.59 & -50.9 & -0.6 & 5.3 & -0.9 \\
\hline & 3 & 2.8 & 2.1 & 0.64 & -54.9 & -4.72 & 1.28 & 1.84 & 57.4 & -2.2 & 3.8 & 2.5 \\
\hline & 4 & 1.9 & 1.2 & 0.36 & -56.9 & -7.52 & -1.52 & 1.04 & -60.3 & -4.1 & 1.8 & 3.4 \\
\hline \multirow{6}{*}{ S. siliquastrum } & 5 & 6.0 & 5.1 & 1.56 & -52.7 & 0.8 & 6.8 & 4.45 & -51.8 & -0.1 & 5.9 & -0.9 \\
\hline & 6 & 4.8 & 4.1 & 1.25 & -53.4 & -0.44 & 5.56 & 3.58 & -52.5 & -1.3 & 4.7 & -0.9 \\
\hline & 7 & 4.1 & 3.5 & 1.07 & -53.0 & -2.14 & 3.76 & 3.05 & -55.5 & 0.4 & 6.3 & 2.5 \\
\hline & 8 & 4.1 & 3.4 & 1.03 & -53.9 & -1.49 & 4.51 & 2.94 & -52.5 & -2.9 & 3.1 & -1.4 \\
\hline & 9 & 3.1 & 2.2 & 0.67 & -53.1 & -6.06 & -0.06 & 1.91 & -56.4 & -2.8 & 3.2 & 3.3 \\
\hline & 10 & 2.8 & 1.8 & 0.54 & -54.8 & -6.12 & -0.12 & 1.56 & -58.5 & -2.4 & 3.6 & 3.7 \\
\hline
\end{tabular}

been reported that the effect of acoustic resonance on gas bubbles should be more pronounced when $k a<<$ 1 , with an instability around $k a=1^{20)}$. We confirmed these reports in our results; Vesicle No. 4 at $200 \mathrm{kHz}$ $(k a=1.04)$ was closer to the resonance model, whereas vesicles No. $7(k a=1.07)$ and $8(k a=1.08)$ were closer to the non-resonance model (Fig. 4, Table 3). Potential bias should be recognized if the sample contains many vesicles whose $k a$ value is nearly 1 . Additional measurements and comparisons are required to make 
the model selection more definite.

Though the source of bias mentioned above should be recognized, theoretical TS equations can be obtained from morphological information and comparative study. For large vesicles $(A \geq 4.1$ at $70 \mathrm{kHz}, A \geq 2.8$ at $200 \mathrm{kHz}$ ), the TS is given by combining the non-resonance model Eq. (4) and relationship between the equivalent radius of the vesicle A and gas bubble a (Eq. [8] or [9]). For $S$. macrocarpum

$$
T S=10 \log \frac{(1.1 A-1.6)^{2}}{4},
$$

and for S. siliquastrum

$$
T S=10 \log \frac{(1.1 A-1.2)^{2}}{4},
$$

For small vesicles ( $A \leq 3.1$ at $70 \mathrm{kHz}, A \leq 1.9$ at 200 $\mathrm{kHz}$ ), the TS is given by combining the resonance model Eq. (7) and the relationship between $A$ and a (Eq. [8] or [9]). Then, for S. macrocarpum

$$
T S=10 \log \frac{(1.1 A-1.6)^{2}}{\left\{\left(f_{r}^{2} / f^{2}\right)-1\right\}^{2}+\delta^{2}},
$$

and for S. siliquastrum

$$
T S=10 \log \frac{(1.1 A-1.2)^{2}}{\left\{\left(f_{r}^{2} / f^{2}\right)-1\right\}^{2}+\delta^{2}},
$$

Shibata ${ }^{8)}$ suggested that the TS of an individual Sargassum plant could be estimated by integrating the TS of all vesicles that contain gas. This implies that, if the amount of gas in a vesicle can be estimated from its size, the TS of an individual plant can be estimated from the size composition of all vesicles. This suggestion is supported by our results, and equations $10,11,12$, and 13 will be useful for estimating the TS of a vesicle or an entire plant.
Shibata ${ }^{8)}$ also suggested that the TS of a small vesicle would fluctuate widely at low frequencies due to resonance effects. Our results confirmed this; the $\Delta T S_{\mathrm{e}}(70 \mathrm{kHz}-200 \mathrm{kHz})$ of small vesicles (Nos. 3, $4,9,10$, Table 3 ) was large (from 2.5 to $3.7 \mathrm{~dB}$ ). The $k a$ of these vesicles at 70 and $200 \mathrm{kHz}$ were smaller and larger than 1, respectively. Because the resonance effect occurred when $k a$ was smaller than 1 , the results indicated that small vesicles resonated at 70 $\mathrm{kHz}$. This suggests that the use of higher frequencies (e.g., $200 \mathrm{kHz}$ ) would be preferable in a field survey, because then the $k a$ of a large number of vesicles would be greater than 1, and hence the TS would not vary widely. In addition, the $k a$ of more vesicles would be around 1 at lower frequencies (e.g., $70 \mathrm{kHz}$ ), for which the experimental TS is not similar to that of either theoretical model. Therefore, an acoustic survey should be conducted at high frequencies to obtain steady acoustic information.

The effect of gas resonance may change with hardness or viscosity of surrounding materials such as shell and surrounding liquid ${ }^{20)}$. Though, these factors were not considered, since the gas was assumed to be a free bubble in this study. However, it is known that the vesicle shell of Sargassum species consist mostly of liquid which is defined as the surrounding material of the free bubble. Moreover, the values of theoretical estimate closed to the values of experimental measurement. Hence, the effect of surrounding materials on gas resonance is to be negligible.

This is the first study to provide information on the gas morphology in vesicles for estimating acoustic characteristics. The range of gas amounts and TSsize equations given in this section should be of value in TS estimation for entire plants and field biomass surveys.

Finally, some authors have suggested that multiple scattering may be important ${ }^{21-23)}$ for overcrowded distributions of gas bubbles. In this effect, the acoustic 
scattering of adjacent bubbles is intricately linked ${ }^{24)}$. Though it is beyond the scope of this paper, the effect of multiple scattering should be examined in future because a Sargassum plant consists of a crowded aggregate of vesicles. Additional comparative studies between theoretical and experimental TS (and TS of vesicle and plants) are required to make the TS estimates of Sargassum plant more reliable.

\section{Acknowledgments}

We thank Dr. Kouichi Sawada and Dr. Koki Abe of the National Research Institute of Fisheries Engineering for help in the TS measurement. We are grateful to Dr. Noboru Murase of the National Fisheries University for useful comments on the classification and structure of Sargassum plants, as well as to all staff of the Laboratory of Fisheries Instrumental, National Fisheries University for their kind support.

\section{References}

1) T. Yoshida, Marine algae of Japan (Uchida Rokakuho Publishing Co., Tokyo, 1998), p. 351-353.

2) N. Murase, "Productivity of Sargassum (Sargassaceae, Phaeophyta) Beds," J. Nat. Fish. Univ., 32, 67-77 (1984).

3) K. Taniguchi, Y. Yamada, "Ecological study on Sargassum patens C. AGARDH and $S$. serratifolium C. AGARDH in the sublittoral zone at Iida Bay of Noto Peninsula in the Japan Sea," Bull. Jap. Sea Reg. Fish Res. Lab., 29, $239-253$ (1978).

4) S. Fuse, "The animal community in the Sargassum belt," Seiri-Seitai., 11, 23-45 (1962).

5) N. Murase, "Ecological study of Sargassum macrocarpum C. Agardh (Fucales, Phaeophyta)," J. Nat. Fish. Univ., 49, 131-212 (2001).

6) T. Komatsu, C. Igarashi, K. Tatsukawa, M. Nakaoka, T. Hiraishi, A. Taira, "Mapping of seagrass and seaweed beds using hydro-acoustic methods," Fish.

$$
\text { Sci., 68, 580-583 (2002). }
$$

7) R. J. Urick RJ, Principles of underwater sound (Translated from Japanese by Tuchiya A), (Kyoritsu Shuppan Co., Tokyo, 1979), p. 239-245.

8) K. Shibata, H. Takayama, "Target strength of Sargassom," Proc. I. O. A., 11, 21-26 (1989).

9) A. L. Brooks, "A study of the swimbladders of selected mesopelagic fish species", in Oceanic sound scattering prediction, N. R. Anderson, B. J. Zahuranec Eds. (Plenum Press, New York, 1977), p. 565-590.

10) M. Strasberg, "The pulsation frequency of nonspherical gas in liquids," J. Acoust. Soc. Am., 25, 536-537 (1953).

11) R. K. Johnson, "Sound scattering from a fluid sphere revisited," J. Acoust. Soc. Am., 61, 375-377 (1977).

12) D. E. Weston, "Sound propagation in the presence of bladder fish", in Underwater Acoustics 2, V. E. Albers Ed. (Plenum Press, New York, 1967), p. 5588.

13) C. Devin, "Survey of thermal, radiation, and viscous damping of pulsation air bubbles in water," J. Acoust. Soc. Am., 31, 1654-1667 (1959).

14) The Marine Acoustics Society of Japan, Fundamentals and Applications of Marine Acoustics (Seizando, Tokyo, 2004), p. 98-113.

15) K. Sawada, Y. Miyanohana, K. Ishii, "Precise target strength pattern measurement in an indoor tank," J. Acoust. Soc. Jpn., 18, 231-238 (1997).

16) K. G. Foote, "Importance of the swimbladder in acoustic scattering by fish: A comparison of gadoid and mackerel target strengths," J. Acoust. Soc. Am., 67, 2084-2089 (1980).

17) H. Yasuma, K. Sawada, K. Miyashita, I. Aoki, "Swimbladder morphology and target strength of myctophid fishes in the Northwestern Pacific," J. Marine Acoust. Soc. Jpn., 35, 17-28 (2008).

18) T. Ajisaka, S. Arai, Y. Ishihi, S. Uwai, K. Kogame, "A study of morphological variations in the genus 
Sargassum (Phaephyceae), especially on the vesicle," Kaiyo monthly., 36, 779-783 (2004).

19) T. Ajisaka, S. Uwai, "On the morphological variations of vesicles and receptacles in Sargassum horneri/S. filicinum-group," Kaiyo monthly., 37, 460-465 (2005).

20) M. Furusawa, "Bubbles and underwater soundsswimbladder and sound scattering by fish," J. Marine Acoust. Soc. Jpn., 16, 5-21 (1989).

21) T. K. Stanton, "Multiple scattering with applications to fish-echo processing," J. Acoust. Soc. Am., 73,
1164-1169 (1983).

22) T. K. Stanton, "Effects of second-order scattering on high resolution sonars," J. Acoust. Soc. Am., 76, 861866 (1984).

23) I. B. Andreeva, A. V. Belousov, "Multiple sound scattering by densely packed shoals of marine animals," ICES J. Mar. Sci., 53, 323-328 (1996).

24) N. Gorska, D. Chu, "On the echo interference in sound backscattering by densely aggregated targets," ICES J. Mar. Sci., 62, 771-778 (2005). 